\title{
Characterization of reference lipids and their degradation products by Raman spectroscopy, nuclear magnetic resonance and gas chromatography-mass spectrometry
}

\author{
Marta S. Maier, ${ }^{a}{ }^{a}$ Dalva L. A. de Faria, ${ }^{b}$ María T. Boschín, ${ }^{c}$ and Sara D. Parera ${ }^{a}$ \\ ${ }^{a}$ Departamento de Química Orgánica, Facultad de Ciencias Exactas y Naturales, Universidad \\ de Buenos Aires, Pabellón 2, Ciudad Universitaria (1428) Buenos Aires, Argentina \\ ${ }^{b}$ Departamento de Química Fundamental, Instituto de Química, Universidade de Sao Paulo, Av. \\ Prof. Lineu Prestes 748 (05508-000) Sao Paulo, Brazil \\ ${ }^{c}$ Centro Nacional Patagónico, Consejo Nacional de Investigaciones Científicas y Técnicas, \\ Boulevard Brown s/n, Puerto Madryn (9120) Chubut, Argentina \\ E-mail: maier@qo.fcen.uba.ar
}

\section{Dedicated to Professor Rosa Lederkremer on her $70^{\text {th }}$ anniversary}

\begin{abstract}
The study of organic residues preserved in objects and materials collected in archaeological sites can provide information on the activities of ancient societies. Degraded animal fats, plant oils, beeswax and plant resins are among the most common organic residues found within ceramic vessels or mixed with inorganic pigments in archaeological pastes. The effects of decay of these organic compounds difficult the direct comparison with modern reference data. The purpose of this work was the use of complementary analytical methods, such as GC-MS, NMR, FT-IR and FT-Raman spectroscopy for the characterization of a reference fat and the degradation products of a thermally aged mixture of a red mineral of the Patagonian region and the fat of an American ostrich (Pterocnemia pennata). Our results showed a decrease in the unsaturated fatty acids with formation of $\mathrm{C}_{8}$ and $\mathrm{C}_{9}$ dicarboxylic acids in the thermally aged fat.
\end{abstract}

Keywords: Lipids, degradation, FT-Raman, gas chromatography, mass spectrometry, archaeological

\section{Introduction}

Archaeometry is the branch of archaeology dealing with applications of scientific methods to the investigation of archaeological materials and its main goals are the knowledge of resources, practices and technological development of ancient societies. Recent research on organic 
residues associated to archaeological fats has proved that lipids are preserved under favorable conditions, in particular in protective matrices, such as pottery vessels, seeds or bones. ${ }^{1}$ The first of the few chemical analysis performed on archaeological samples from Argentinian Patagonia has focused on the identification of inorganic pigments in rock art. ${ }^{2}$ Recently, we have collected the first data on the chemical composition of organic binders mixed with mineral pigments from samples of rock art and pastes buried at Septentrional Patagonian archaeological sites. ${ }^{3}$ Our results showed that natural products as vegetable oils, beeswax and animal fats might have been used as binders for the preparation of colors for painting. Reports from foreign travelers in Patagonia during the XVIII and XIX centuries give account of the use of local animal fats (ostrich and guanaco) mixed with red clays for corporal and facial painting as well as for the decoration of their shelters. ${ }^{4}$

The characterization of a degraded animal fat as the binder in two ochre painting residues (pastes) found in stratigraphic position in the archaeological site Cave Loncomán (Río Negro Province, Argentina $)^{5}$ and the high abundance of unsaturated fatty acids $\left(\mathrm{C}_{16: 1}\right.$ and $\left.\mathrm{C}_{18: 1}\right)$ in the archaeological lipids prompted us to study the factors influencing lipid degradation within mineral matrices. Therefore, we have performed artificial thermal ageing tests on a mixture of a reference local mineral containing hematite and an animal fat of an American ostrich (Pterocnemia pennata), typical of the Argentine Patagonia with the aim to compare the aged fat with the lipid composition of the archaeological pastes.

Due to the complexity of the system, a combination of spectroscopic and chromatographic methods, such as FT-IR, FT-Raman, NMR, GC and GC-MS were applied to address the problem.

\section{Results and Discussion}

This work was motivated by a study on two archaeological pastes (1 and 2) aged 2000 B.P. $\left({ }^{14} \mathrm{C}\right)$, found on the top of the early occupations of Cave Loncomán. This archaeological site is completely covered with engravings that represent human footfalls, local fauna and geometric designs, some over painted in red and orange colors. The pastes might have been used in the preparation of the colors for painting or as facial and corporal paintings. Pastes $\mathbf{1}$ and $\mathbf{2}$ are a mixture of pigmented (yellow-orange and red-orange) clays with a binder which proved to be a fat. $^{6}$ The FT-IR spectra of the archaeological samples showed that the organic phase has degraded to a large extent in the pastes and only the inorganic components contribution could be observed in the spectrum. ${ }^{5}$ The extracts obtained from both pastes with a chloroform:methanol (2:1) mixture were analysed by FT-IR and compared with that of a reference fat obtained from an American ostrich (P. pennata) (Fig. 1). 


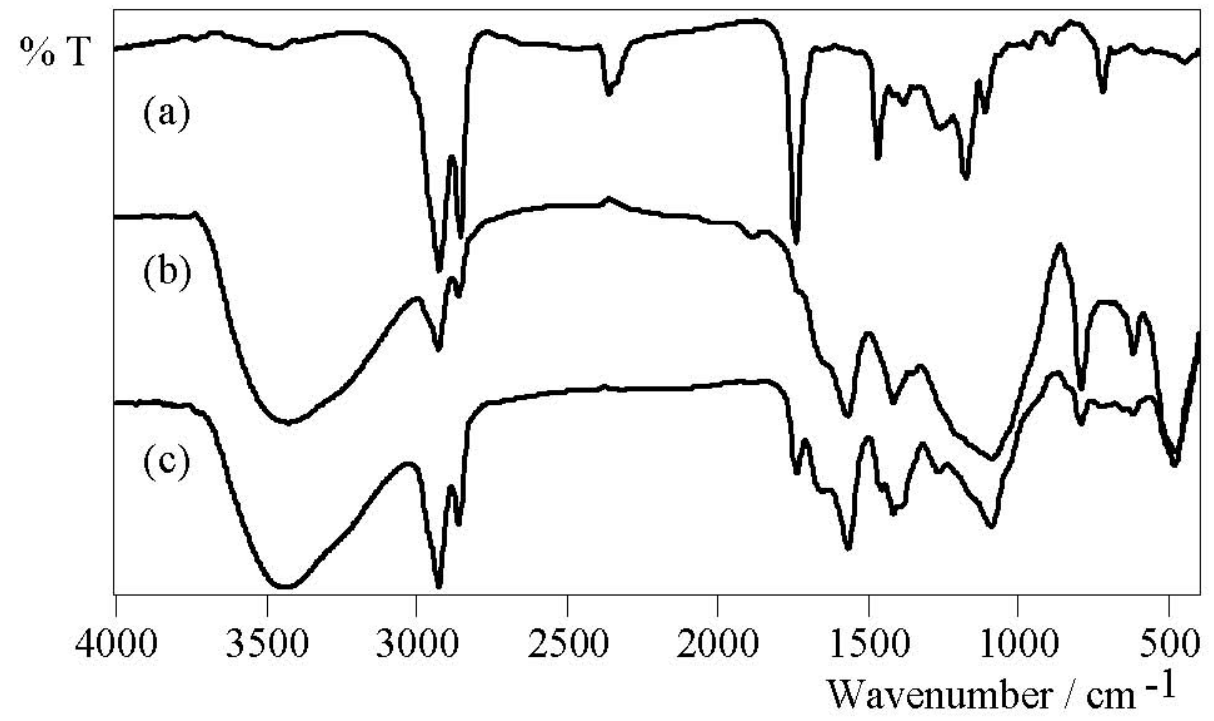

Figure 1. FT-IR (KBr) spectra of chloroform:methanol (2:1) extracts from: (a) P. pennata fat (reference); (b) paste 1; (c) paste 2.

The FT-IR spectra are not very helpful in the sample discrimination as the chemical groups present are nearly the same and it is difficult to ascribe the $c a .1750 \mathrm{~cm}^{-1}$ band in the archaeological pastes because it can arise from carboxyl vibration in carboxylic acids or in triacylglycerols. As reported in a previous work ${ }^{5}$ this point was clarified by treating the reference fat with a $4 \% \mathrm{KOH}$ in $\mathrm{MeOH}$ solution, aiming the conversion of the triacylglycerols to a mixture of fatty acids (saponification) which were further transformed into the corresponding potassium salt. The FT-IR obtained from the free fatty acids mixture and salt clearly indicated that the lipids in the archaeological samples corresponded to free fatty acids. ${ }^{5}$ It can thus be concluded that hydrolysis is the main degradation route for the organic compounds originally used in the paint preparation. Nevertheless, the effect of degradation upon the samples could change its composition and for this reason a small amount of an inorganic pigment was mixed to the reference ostrich fat and submitted to an artificial ageing assay by heating at $39^{\circ} \mathrm{C}$ for 40 days under atmospheric conditions. The inorganic pigment (or reference pigment) is a naturally occurring coloured clay containing quartz, kaolinite, illite and hematite, as determined by XRD. The mixture was analysed by FT-IR (Fig. 2), FT-Raman (Fig. 3), GC-MS (Table 1) and NMR (Table 2) before and after the ageing process. 


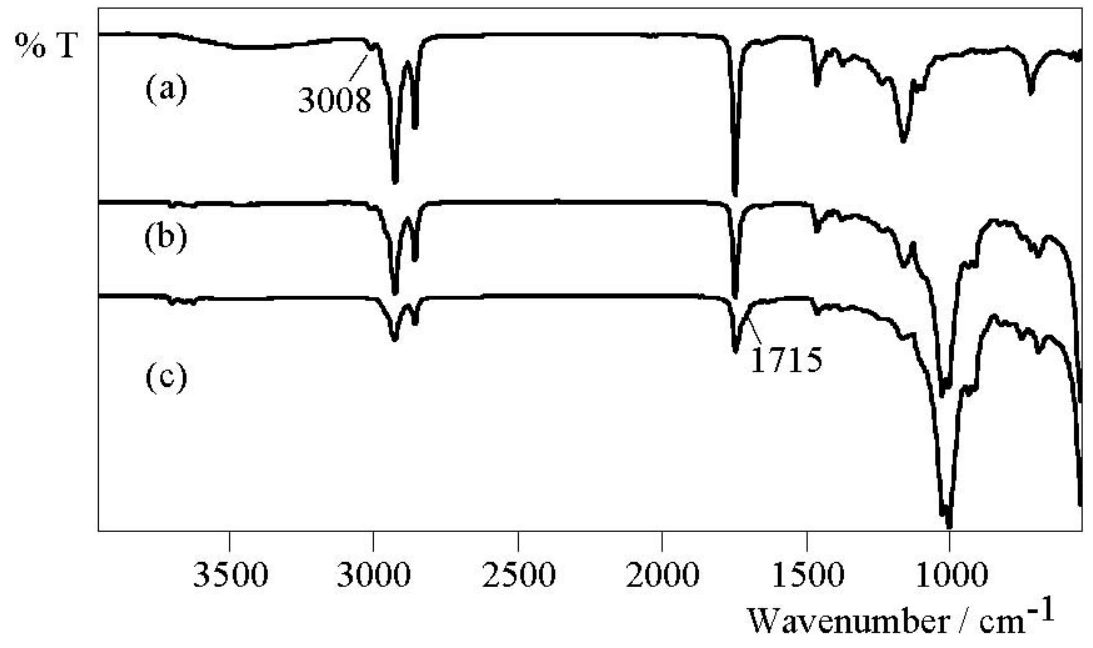

Figure 2.- FT-IR (ATR) spectra of (a) P. pennata fat (reference fat); (b) unaged reference fat and mineral mixture and (c) aged reference fat and mineral mixture.

Figure 2 presents the FT-IR (ATR) spectra of the unprocessed fat, its mixture with the reference pigment and that of the artificially aged mixture. Unprocessed fat and the unaged mixture provided equivalent spectra except for the bands below $1200 \mathrm{~cm}^{-1}$, due to the inorganic phase absorptions. However the spectrum of the aged sample showed some clear changes when compared with the unaged one. The most evident change was a decrease in the intensity of the $v(=\mathrm{CH})$ mode at ca. $3010 \mathrm{~cm}^{-1}$. Furthermore, the presence of a shoulder at $1715 \mathrm{~cm}^{-1}$ causes a shift (from 1745 to $1742 \mathrm{~cm}^{-1}$ ) and broadening in the $v(\mathrm{COO})$ band at $1745 \mathrm{~cm}^{-1}$. The changes in the FT-IR spectra suggested an oxidation process of the unsaturated bonds.

In the FT-Raman spectra of the unaged and aged mixture (Fig. 3) an emission background is observed, affecting data quality. However, the changes in the aged sample observed in the FT-IR spectrum are also observed in the Raman spectrum taking into account the differences between both techniques: the vanishing of the $3010 \mathrm{~cm}^{-1}$ band in the aged sample and the alterations in the intensity of the carboxylic COO stretching (albeit much weaker in the Raman spectra) can be clearly noticed. The $\mathrm{C}=\mathrm{C}$ stretching observed at $1656 \mathrm{~cm}^{-1}$ in the unprocessed fat (weak in the FT-IR spectrum) is still observed in the unaged sample but not in the aged one, thus confirming that the double $\mathrm{C}=\mathrm{C}$ bonds in the fatty acids underwent oxidation during the ageing procedure. The strong bands observed below $1100 \mathrm{~cm}^{-1}$ in the FT-IR spectrum due to silicate and other inorganic species are not present in the Raman spectrum since such species are weak light scatterers but the hematite peaks are observed below $700 \mathrm{~cm}^{-1}\left(297,412\right.$ and $\left.612 \mathrm{~cm}^{-1}\right)$. 


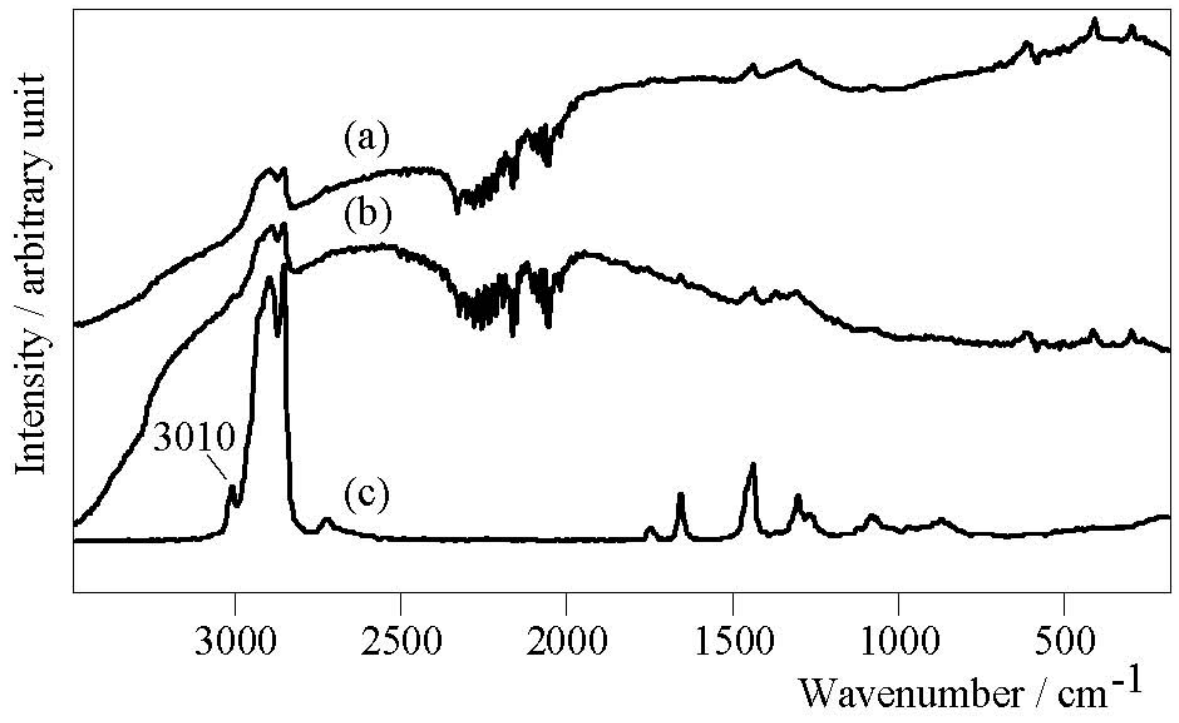

Figure 3.- FT-Raman spectra of: (a) aged reference fat and mineral mixture; (b) unaged reference fat and mineral mixture and (c) reference fat.

Comparative analysis by GC and GC-MS of the unaltered mixture and the aged one (Table 1) showed a significant decrease in the amount of palmitoleic $\left(\mathrm{C}_{16: 1}\right)$ and oleic $\left(\mathrm{C}_{18: 1}\right)$ acids $(5.0 \%$ to $0.5 \%$ and 27.0 to $3.4 \%$, respectively) in the aged mixture. Such acids are monounsaturated and the results are consistent with an oxidative mechanism in opposition to the hydrolysis reaction observed for the archaeological samples. Furthermore, the ageing procedure led to the formation of a significant amount of short chain dicarboxylic acids, not observed for the pastes. These diacids are formed during the oxidation of unsaturated fatty acids and are known to be produced through radical reactions via hydroperoxide intermediates. ${ }^{7}$

Table 1. Fatty acid methyl esters (FAMEs) composition of archaeological pastes $\mathbf{1}$ and $\mathbf{2}$, reference fat and thermally aged reference fat

\begin{tabular}{ccccccccc}
\hline Fatty acids & $\mathrm{C}_{14: 0}$ & $\mathrm{C}_{15: 0}$ & $\mathrm{C}_{16: 1}$ & $\mathrm{C}_{16: 0}$ & $\mathrm{C}_{18: 1}$ & $\mathrm{C}_{18: 0}$ & $\mathrm{C}_{8}$ (diacid) & $\mathrm{C}_{9}$ (diacid) \\
\hline Unaltered mixture & traces & traces & $5.0 \%$ & $34.3 \%$ & $27.0 \%$ & $5.2 \%$ & - & - \\
Aged mixture & $1.5 \%$ & $0.5 \%$ & $0.5 \%$ & $56.1 \%$ & $3.4 \%$ & $12.3 \%$ & $2.3 \%$ & $7.3 \%$ \\
Paste 1 & $1.5 \%$ & $1 \%$ & $4.7 \%$ & $28.5 \%$ & $20.6 \%$ & $8.3 \%$ & - & - \\
Paste 2 & - & traces & $8.7 \%$ & $29.8 \%$ & $16.1 \%$ & $13.2 \%$ & - & - \\
\hline
\end{tabular}

The position of double bonds in the palmitic and oleic acids is directly related to the formation of $\mathrm{C}_{8}$ and $\mathrm{C}_{9}$ diacids, respectively. Another change was the increase in the amount of the saturated acids $\mathrm{C}_{16: 0}(34.3 \%$ to $56.1 \%)$ and $\mathrm{C}_{18: 0}(5.2 \%$ to $12.3 \%)$ in the aged mixture. Some authors have suggested that a $\beta$-oxidation process with further reduction of the double bond in oleic acid could be involved in the formation of palmitic acid from oleic acid. ${ }^{7}$ 
As can be seen in Table 1, the chemical composition of the FAMEs of the solvent extracts of both pastes are similar to that of the reference fat, confirming the source of an animal fat as the binder.

NMR analysis of the reference mixture and the artificially aged one confirmed the results described above (Table 2). The ${ }^{1} \mathrm{H}$ and ${ }^{13} \mathrm{C}$ NMR spectra of the reference mineral and fat mixture showed typical signals due to triacylglycerols. ${ }^{8}$ Signals at $\delta 1.97 \mathrm{ppm}\left(\mathrm{CH}=\mathrm{CHCH}_{2}\right)$ and 5.34 ppm (olefinic proton) were clearly reduced in the ${ }^{1} \mathrm{H}$ NMR spectrum of the organic extract of the aged mixture. This was confirmed by vanishing of the corresponding carbon signals at $\delta=27$ and $129 \mathrm{ppm}$ in the ${ }^{13} \mathrm{C}$ NMR spectrum of the aged sample.

Table 2. ${ }^{1} \mathrm{H}-\mathrm{NMR}$ and ${ }^{13} \mathrm{C}-\mathrm{NMR}$ data of unaged reference fat and mineral mixture (a) and aged reference fat and mineral mixture $(\mathbf{b})$

\begin{tabular}{|c|c|c|c|c|}
\hline & & $\mathbf{a}$ & & b \\
\hline $\mathrm{C}, \mathrm{H}$ & ${ }^{1} \mathrm{H}(\mathrm{m}, \mathrm{J} \mathrm{Hz})$ & ${ }^{13} \mathrm{C}$ & ${ }^{1} \mathrm{H}(\mathrm{m}, \mathrm{J} \mathrm{Hz})$ & ${ }^{13} \mathrm{C}$ \\
\hline \multirow[t]{2}{*}{ C-1, C-3 Gly } & $4.10(\mathrm{dd}, 12.1,5.9)$ & 61.97 & $4.14(\mathrm{dd}, 11.6,5.7)$ & 62.05 \\
\hline & $4.26(\mathrm{dd}, 12.1,4.4)$ & & $4.29(\mathrm{dd}, 11.9,4.3)$ & \\
\hline C-2 Gly & $5.23(\mathrm{~m})$ & 68.78 & $5.25(\mathrm{~m})$ & 68.88 \\
\hline \multirow[t]{2}{*}{$\mathrm{C}=\mathrm{O}$} & - & 172.69 & - & 173.30 \\
\hline & & 173.12 & & \\
\hline \multirow[t]{3}{*}{$\mathrm{OCOCH}_{2}$} & $2.28(\mathrm{t}, 7.5)$ & 33.89 & $2.31(\mathrm{t}, 7.3)$ & 33.95 \\
\hline & & 33.91 & & 34.03 \\
\hline & & 34.06 & & 34.09 \\
\hline $\mathrm{OCOCH}_{2} \mathrm{CH}_{2}$ & $1.57(\mathrm{bs})$ & 24.75 & $1.60(\mathrm{bs})$ & 24.84 \\
\hline \multirow[t]{2}{*}{$\mathrm{CH}_{2} \mathrm{CH}=$} & $1.97(\mathrm{~m})$ & 27.04 & - & - \\
\hline & & 27.10 & & \\
\hline \multirow[t]{3}{*}{$\mathrm{CH}=\mathrm{CH}$ cis } & $5.30(\mathrm{~m})$ & 129.53 & $5.34(\mathrm{~m})$ & - \\
\hline & & 129.56 & & \\
\hline & & 129.86 & & \\
\hline \multirow[t]{2}{*}{$-\mathrm{CH}_{2-}$} & $1.22(\mathrm{~m})$ & 28.93- & $1.25(\mathrm{~m})$ & $28.90-$ \\
\hline & & 29.65 & & 29.68 \\
\hline $\mathrm{CH}_{3}$ & $0.84(\mathrm{t}, 7.0)$ & 13.99 & $0.87(\mathrm{t}, 7.0)$ & 14.11 \\
\hline
\end{tabular}

\section{Conclusions}

Artificially ageing experiments of a mixture of a reference mineral and an ostrich fat were performed in order to get insight into the degradation process observed in archaeological pastes. The results obtained by a combination of analytical techniques clearly indicated that the aged mixture underwent an oxidative degradation process, not observed in the archaeological pastes. 
The high content of unsaturated fatty acids as palmitoleic $\left(\mathrm{C}_{16: 1}\right)$ and oleic $\left(\mathrm{C}_{18: 1}\right)$ acids, similar to the fatty acid profile of the reference fat, suggest that the archaeological lipids might have been protected from oxidative conditions within the mineral matrices. The hydrolysis of triacylglycerols in the archaeological pastes was the principal degradation process observed and this can be attributed to chemical or bacterial action. Bacterial mediated decay experiments of lipids have shown a rapid decrease in triacylglycerol abundance with production of free fatty acids. ${ }^{8}$ Considering the dry conditions of the region where the pastes were found and the low content of organic material in the archaeological samples, bacterial action might have played a very important role in lipid degradation in the archaeological pastes of Loncomán Cave.

\section{Experimental Section}

General Procedures. The Raman spectra were obtained in a Bruker RFS 100/S, fitted with a liquid $\mathrm{N}_{2}$ cooled Ge detector. Sample excitation was performed with the $1064 \mathrm{~nm}$ line of a $\mathrm{Nd}^{3+} /$ YAG laser. Single Bounce ATR data were obtained in a Bomem MB-100 Arid Zone FT-IR spectrometer using a Silver Gate ATR accessory (Specac). ${ }^{1} \mathrm{H}$ and ${ }^{13} \mathrm{C}$ NMR spectra were recorded in $\mathrm{CDCl}_{3}$ on a Bruker AM 500 spectrometer. GC was performed on a Hewlett-Packard $5890 \mathrm{~A}$ chromatograph equipped with a flame ionization detector and an ULTRA 2 column (30 m x $0.25 \mathrm{~mm}$ i.d.). Temperature program: $1 \mathrm{~min}$ of isothermal at $100{ }^{\circ} \mathrm{C}$ and then 100 to $290{ }^{\circ} \mathrm{C}$ at $10{ }^{\circ} \mathrm{C} \mathrm{min}^{-1}$, followed by a $10 \mathrm{~min}$ hold at $290^{\circ} \mathrm{C}$ (10 $\left.\mathrm{min}\right)$. GC-MS was performed on a TRIO-2 VG mass spectrometer coupled to a Hewlett-Packard 5890 chromatograph. XRD analysis was carried out on a Philips diffractometer PW 1050 using copper radiation and nickel anticathode.

Animal fat and marrow of an American ostrich (Pterocnemia pennata) and a guanaco (Lama guanicoe) were provided by local inhabitants of Estancia Loma Blanca and Potrero Consumo, Río Negro Province. The reference red mineral was obtained from Sitio Florentino, Estancia Loma Blanca, Río Negro Province.

Ageing of the mixture of the reference mineral and ostrich fat. The mixture was spread on a Petri dish and heated at $39{ }^{\circ} \mathrm{C}$ in a Boekel benchtop incubator for 40 days in room humidity conditions.

Solvent extraction of the archaeological pastes and the aged mixture. The samples were extracted using chloroform/methanol $(2: 1 \mathrm{v} / \mathrm{v}, 15 \mathrm{ml}, 2 \mathrm{x} 15 \mathrm{~min}$ sonication) at room temperature. The total lipid extracts were then centrifuged (15 min, $3200 \mathrm{rpm}$ ), decanted and filtered through celite. The filtrates were then dried under a stream of nitrogen and stored at -25 ${ }^{\circ} \mathrm{C}$ until required for derivatization and analysis.

Derivatization of fat samples. Fatty acid methyl esters (FAMEs) were prepared by treating the unaged and aged mixtures of the reference mineral and the ostrich fat with $\mathrm{HCl} 2 \%$ in methanol $(0.5 \mathrm{ml})$ at $60{ }^{\circ} \mathrm{C}$ for $2 \mathrm{~h}$. After cooling, water $(0.5 \mathrm{ml})$ was added and the mixture was extracted with chloroform ( $3 \times 0.5 \mathrm{ml})$, and the solvent evaporated under nitrogen. 


\section{Acknowledgements}

This research was supported by the Agencia Nacional de Promoción Científica y Tecnológica (ANPCyT) (Grant BID 1201/OC-AR 0403399). We are indebted to UMYMFOR (CONICETFCEN, UBA) for NMR and mass spectra. D. L. A. F. acknowledges Fapesp and CNPq (Brazil) for research grants and fellowships. M. S. M. and M. T. B. are Research Members of the National Research Council of Argentina (CONICET).

\section{References}

1. (a) Evershed, R. P.; Dudd, S. N.; Copley, M. S.; Stott, A. W.; Mottram, H.; Buckley, S. A.; Crossman, Z. Acc. Chem. Res. 2002, 35, 660. (b) Regert, M.; Garnier, N.; Decavalla, O.; Cren-Olivé, C.; Rolando, Ch. Meas. Sci. Technol. 2003, 14, 1620. (c) Copley, M. S.; Bland, H. A.; Rose, P.; Horton, M.; Evershed, R. P. Analyst 2005, 130, 860.

2. (a) Iñiguez, A. M.; Gradin, C. J. Relaciones de la Sociedad Argentina de Antropología 1977, XI, 121. (b) Aschero, C. A. Cuadernos del Instituto Nacional de Antropología. 1983-1985, $V$, 201. (c) Barbosa, C. E.; Gradin, C. J. Relaciones de la Sociedad Argentina de Antropología 1986-1987, XVII, 143. (d) Wainwright, I. N. M.; Helwig, K.; Rolandi, D. S.; Gradin, C.; Podestá, M. M.; Onetto, M.; Aschero, C. A. Preprints of the Triennial Meeting of the ICOM Committee for Conservation, Río de Janeiro, ICOM 2002, II, 582.

3. Boschín, M. T.; Seldes, A. M.; Maier, M. S.; Casamiquela; R. M.; Ledesma, R.; Abad, G. Zephyrus 2002, 55, 183.

4. Onelli, C. Trepando los Andes. El Elefante Blanco, Buenos Aires, 1st. ed., 1998.

5. Maier, M. S., de Faria, D. L. A.; Boschín, M. T.; Parera, S. D. Vibrational Spectroscopy (submitted).

6. Maier, M. S.; Boschín, M. T.; Parera, S. D.; del Castillo Bernal, M. F. Proceedings of the Sixth Infrared and Raman Users Group Conference (IRUG6), Florence, il Prato Publishers 2005, 218.

7. Mills, J. S.; White, R. The Organic Chemistry of Museum Objects, Butterworths: London, $2^{\text {nd }}$ ed., 1994.

8. (a) Adler, M. T.; Fazio, A.; Bertoni, M. D.; Rosso, M. L.; Maier, M. S.; Thell, A. Bibliotheca Lichenologica 2004, 88, 1. (b) Cateni, F.; Falsone, G.; Zilic, J.; Bonivento, P.; Zacchigna, M.; Zigon, D.; Sosa, S.; Altinier, G. Arkivoc 2004, V, 54.

9. Dudd, S. N.; Regert, M.; Evershed, R. P. Org. Geochem. 1998, 29, 1345. 